\title{
Reflexiones en torno a los procesos de patrimonialización del patrimonio cultural inmaterial
}

\begin{abstract}
Jesús Mendoza Mejía ${ }^{1}$
Resumen: La constitución del patrimonio cultural ha sido abordada desde diferentes ángulos planteando actores y relaciones de poder existentes. En el caso del patrimonio inmaterial es de relevancia comprender los procesos de patrimonialización como la construcción de significado y sentido de los elementos culturales, a través de la asignación de valores, que los agentes culturales hacen con ciertas finalidades; así como un reflejo de la sociedad global. En este sentido, es posible hablar de una patrimonialización en red, en la cual diversos actores confluyen en un sistema organizado en redes, nodos y flujos. Redes o enlaces que conectan o no a actores, con nodos interconectados con mayor o menor importancia; en donde lo que fluye son valores, intereses y significados que conectan o desconectan actores, una red que siempre está en continua reconfiguración.

Palabras-clave: Patrimonialización en red; patrimonio cultural inmaterial; sociedad red.
\end{abstract}

\section{Reflexões sobre os processos de patrimonialização do patrimônio cultural imaterial}

Resumo: A constituição do patrimônio cultural foi abordada sob diferentes ângulos, propondo atores e relações de poder existentes. No caso do patrimônio intangível, é importante compreender os processos de patrimonialização como a construção do significado e do significado dos elementos culturais, através da atribuição de valores, que os agentes culturais fazem com determinados fins; bem como um reflexo da sociedade global. Nesse sentido, é possível falar de uma patrimonialização de rede, na qual diversos atores convergem em um sistema organizado em redes, nodos e fluxos. Redes ou links que se conectam ou não com atores, com nós interconectados com maior ou menor importância; onde o que flui são valores, interesses e significados que conectam ou desconectam atores, uma rede que sempre está em reconfiguração contínua.

Palavras-chave: Patrimonialização em rede; patrimônio cultural imaterial; sociedade em rede.

\section{Reflections on the heritagisation of intangible cultural heritage:}

Abstract: The constitution of the cultural heritage has been approached from different angles, proposing existing actors and power relations. In the case of intangible heritage, it is important to understand heritagisation processes such as the construction of meaning and meaning of cultural elements, through the assignment of values, that cultural agents do with certain purposes; as well as a reflection of the global society. In this sense, it is possible to speak of a network heritagisation, in which diverse actors converge in a system organized in networks, nodes and flows. Networks or links that connect or not to actors, with interconnected nodes with greater or lesser importance; where what flows are values, interests and meanings that connect or disconnect actors, a network that is always in continuous reconfiguration.

Keywords: Network heritagisation; intangible cultural heritage; network society.

(c) (1)(5)

DOI: https://doi.org/10.26512/patryter.v1i2.7177

Como citar este artigo: Mejía, J. M. (2018). Reflexiones en torno a los procesos de patrimonialización del patrimonio cultural inmaterial. PatryTer - Revista Latinoamericana e Caribenha de Geografia e Humanidades, 1 (2), 72 83. DOI:https://doi.org/10.26512/patryter.v1i2.7177.

Recebido: 22 de maio, 2018. Aceite: 29 de junho, 2018. Publicado: 27 de setembro, 2018.

${ }^{1}$ Maestro en Estudios Políticos y Sociales por la Universidad Nacional Autónoma de México: Coyocan, Distrito

Federal, México. Email: jesus.mendoza@enp.unam.mx. 


\section{Introducción}

El patrimonio cultural inmaterial (PCI) por mucho tiempo ha sido abordado con otros nombres: tradición oral, folclor, costumbres, patrimonio etnológico, etc. El concepto de PCI surge como un discurso alterno al del patrimonio monumental con el fin de dotar de representatividad a aquellos países, principalmente del hemisferio sur, que no contaban con los referentes de monumentalidad que eran admirados por Occidente; fue a través del patrimonio inmaterial que se destacaron y reconocieron los rasgos subjetivados de las culturas como Patrimonio de la Humanidad (Smith \& Akagawa, 2009; Arizpe, 2011b; Bortollotto, 2011; Harrison 2013).

En este sentido, el patrimonio cultural será entendido como "aquello, que como humanos, valoramos o 'queremos transmitir a futuras generaciones'. Denota recursos culturales performáticos, incluyendo la danza, música, lenguaje, tradición oral y sistemas de conocimientos, construcciones monumentales, sitios arqueológicos, cultura material e ideología" (Kearney, 2009, p. 210). Lourdes Arizpe (2006, 2011a) menciona que el patrimonio cultural inmaterial debería entenderse como "un proceso de creación que comprende habilidades y posibilita factores, productos, repercusión y valor económico" (Arizpe, 2011a, p. 53); es decir, el PCI hace referencia a un proceso creativo en el que se ponen en juego los valores comunitarios, la memoria colectiva, los conocimientos, técnicas y saberes, los actos performativos, las formas de interacción, entre otros, que son parte del momento de creación, recreación y transmisión del mismo PCI.

A partir de esto es posible entender al PCI como aquellos elementos culturales que son detentados y accionados por ciertos grupos o individuos de cualquier comunidad, que son significados y pueden tener referentes materiales, son transmitidos de generación en generación. Se trata de un proceso en continua construcción y no un acto finito.

El presente artículo busca comprender los procesos de patrimonialización en torno al patrimonio cultural inmaterial en el contexto de la sociedad en red. Se propone comprender al patrimonio como una construcción social que está vinculado con las capacidades de agencia en el reconocimiento, selección u oficialización del mismo. Así mismo, se propone comprender cómo estos procesos de patrimonialización ocurren en red en la cual diversos actores confluyen en un sistema organizado de redes, nodos y flujos a través de los cales fluyen o friccionan valores, intereses y significados. Para ello se retoma el caso del Xantolo, expresión regional del Día de Muertos en el Estado de Hidalgo, México para comprender la patrimonialización en red en la cual diversos actores participan y se articulan en distintos niveles; los cuales pueden interactuar o no, generando conexiones.

Este artículo forma parte del proyecto de investigación titulado "Xantolo: patrimonialización y salvaguardia en red" para obtener el grado de Maestro en Estudios Políticos y Sociales en la Universidad Nacional Autónoma de México. Esta investigación ha sido realizada gracias al apoyo del Programa de Apoyo a los Estudios de Posgrado (PAEP) de la UNAM y del Consejo Nacional de Ciencia y Tecnología (CONACyT).

Como parte de este proyecto más amplio, la propuesta metodológica fue proyectada para realizarse a partir de la investigación documental y de campo en Hidalgo. Se analizaron las políticas y planes de salvaguardia generados por el estado de Hidalgo; así como el respectivo expediente de declaratoria ante la UNESCO con el objetivo de comprender a detalle su composición y las políticas de salvaguardia de dicho elemento.

Se realizó trabajo de campo en Huejutla, Hidalgo, particularmente durante la festividad del Xantolo, con el objetivo de comprender la política cultural y su salvaguardia en conjunto con la propia práctica y así comprender los procesos de patrimonialización en red. Se aplicaron entrevistas estructuradas para conocer las posturas de los actores relacionados con las declaratorias principalmente a encargados a nivel municipal y estatal; se realizaron además observación, entrevistas abiertas y encuestas breves para comprender los significados y formas de patrimonialización de la práctica, especialmente en el sector joven.

Así mismo, se retomó la etnografía digital como metodología de análisis y observación de los fenómenos contemporáneos dentro del patrimonio cultural inmaterial, para comprender las prácticas digitales relacionadas con el Xantolo; se hizo un registro audiovisual con el objetivo de crear material para el análisis de las prácticas transmediáticas y la experiencia de los agentes culturales en la festividad; y además se analizó el material audiovisual existente, para vislumbrar la construcción del Xantolo y del Día de muertos presente en documentales, videos de producción local e imágenes de Instagram. 
Jesús Mendoza Mejía

\section{Patrimonialización, miradas conceptuales}

La constitución del patrimonio estaba relacionada "con el desarrollo del nacionalismo del siglo XIX y la modernidad liberal" (Smith, 2006, p. 17), en donde lo que lo definía tenía relación con la forma en la que las sociedades modernas se concebían así mismas (Harrison, p. 2013). A partir de esto podemos entender el desarrollo teórico que Llorenç Prats (1997, 2005) hace en torno al patrimonio cultural; él lo llama invención y la construcción del patrimonio cultural, ya que el patrimonio cultural no es algo dado por naturaleza ni un fenómeno social universal. Esta invención del patrimonio cultural tendrá relación con un proceso de manipulación de ciertas expresiones o referentes culturales, mientras que la construcción tendrá que ver con estrategias de legitimación, principalmente extraculturales; existen tres criterios que rigen esto: la naturaleza, la historia y la inspiración creativa.

Los primeros dos criterios (la naturaleza y la historia) tendrán que ver con formas extrahumanas de otorgar valor a ciertos bienes, refieren al patrimonio cultural y a la antigüedad de los bienes culturales. Mientras que, en el caso de la inspiración creativa o el genio creativo, Prats (1997) menciona que "representa la excepcionalidad cultural, la individualidad que trasciende, y por tanto transgrede las reglas y capacidades culturales que rigen para el común" (Prats, 1997, p. 23).

En este sentido, Harrison (2013) lo denomina como la construcción de un patrimonio oficial basado en la conservación de sus valores artísticos, históricos, científicos, sociales y recreativos; planteando una patrimonialización selectiva del pasado. Así mismo, este autor plantea una crisis de los modelos de conceptualización del patrimonio cultural (Harrison, 2013, p. 18), que se conjunta con el creciente reconocimiento del aspecto inmaterial del patrimonio, motivado por las discusiones en torno a la conceptualización de la cultura y la diversidad cultural por parte de antropólogos como Margaret Mead, Ruth Benedict y Ralph Linton, quienes comprenden la cultura como modelos de comportamiento aprendidos y transmitidos, solidificados en artefactos y que son compartidos por grupos o un solo individuo.

Así, se constituyen patrimonios nooficiales en los que existe un giro de lo distinguible/notable a lo cotidiano, como un "conjunto de prácticas repetitivas, atrincheradas y algunas veces ritualizadas que vinculan los valores, creencias y memorias de las comunidades en el presente con aquellas del pasado" (Harrison, 2013, p. 18), en el que los individuos están directamente vinculados con la forma de significar su patrimonio
Reflexiones en torno a los procesos de patrimonialización o, como lo plantea Prats (1997), en cuanto a las activaciones patrimoniales.

La activación del patrimonio cultural que Prats (1997) planteó para el patrimonio tangible tendrá que ver con ciertas capacidades y poderes políticos para crear patrimonio. A pesar de ello, estos "repertorios patrimoniales también pueden ser activados desde la sociedad civil, por agentes sociales diversos $[\ldots]$ aunque, para fructiferar, siempre necesitarán el soporte [...] del poder" (Prats, 1997, p. 35).

Es así como el patrimonio cultural se puede definir como los bienes o expresiones, producto de prácticas culturales, que cuentan con valores y significados reconocidos por una comunidad. Los individuos "asumen la herencia y el dominio de un determinado patrimonio cultural [...] de un conjunto de bienes, unos tangibles y otros intangibles, que abarcan desde un territorio hasta formas de organización social, conocimientos, símbolos, sistemas de expresión y valores que consideran suyos" (Bonfil, 2004, p. 191). Es decir, existe cierto nivel de identificación y relación con el patrimonio que lo vuelve un patrimonio local; que en términos de Llorenç Prats (2005) está "compuesto por todos aquellos objetos, lugares y manifestaciones locales que [...] guardan una relación metonímica con la externalidad cultural" (Prats, 2005, pp. 23-24). Los patrimonios locales crean un sentimiento de adscripción e identificación; son entonces generadores de comunidad, cuya importancia radica en la memoria colectiva del pueblo desde la cual se le ve y se le asocia con uno mismo, con el propio devenir histórico.

El patrimonio surge cuando una comunidad cultural le da forma a esos lazos de conectividad y pertenencia, y otorga calidad de representación a los bienes tangibles e intangibles que elige valorar. Hace visibles dichos lazos creando constantemente significados que se plasman en danzas, cantos, esculturas, obras arquitectónicas, y tantas otras formas creativas. Cabe reconocer, por lo tanto, que el patrimonio se halla en constante redefinición y movimiento. Dicho de otra manera, lo que mantiene con vida al patrimonio es que los individuos de la comunidad cultural recuerden y recreen su significado en cada periodo histórico (Arizpe, 2006, p. 254).

El patrimonio cultural inmaterial, como cualquier patrimonio es cambiante debido a las diversas significaciones que se le otorgan a lo largo del tiempo; "las patrimonializaciones forman procesos complejos de selección y recalificación, que implican valores más o menos compartidos, reconocidos y establecidos a lo largo del tiempo" (Bondaz, Isnart \& Leblon, 2012, p. 9). Es importante destacar que el patrimonio cultural 
"tiene que ser experimentado para ser patrimonio" (Smith, 2006, p. 47); es decir, solo a través del uso de los referentes patrimoniales podrá existir patrimonio. El uso será lo que le dé vitalidad, significado e importancia al PCI; "implica un sentido de continuidad y de materiales compartidos, costumbres y expresiones verbales que continúan practicándose en y entre ciertos grupos" (Sims, 2005, p. 65). El PCI se estructura como saberes o memorias que son puestas en acción tras una transmisión en la que "se comunica y crea comunidad" (Amengual, 2008, p. 46).

Otro de los aspectos relevantes que destacan al PCI es su practicidad, es decir la capacidad performativa que conllevan las prácticas inmateriales. "El performance es una actividad expresiva que requiere participación, realza nuestro disfrute de la experiencia, e invita a responder" (Sims, 2005, p. 128). En este sentido, las prácticas performáticas permiten generar procesos de encarnación de la memoria; es decir, generar procesos de puesta en escena de las memorias locales a través del cuerpo, produciendo a través de la práctica un sentimiento de arraigo y pertenencia identitaria.

Un último punto por abordar dentro de las diversas características del patrimonio inmaterial serán las formas de transmisión. Cabe mencionar que la transmisión es uno de los principales mecanismos a partir de las cuales es posible salvaguardar el patrimonio intangible. En este sentido, Mosterín (1993, pp. 93-94) propone tres modos de transmisión cultural: vertical, oblicua y horizontal. La vertical se realiza de padres a hijos, de generación en generación; la horizontal se realizará entre personas de una misma generación y la oblicua entre individuos de distinta generación sin lazos de parentesco, es decir, a través de la propia interacción comunitaria.

El patrimonio inmaterial según Chiara Bortolotto (2011) puede ser comprendido como "las propias prácticas culturales (en un sentido descriptivo) o las prácticas culturales que pasan por un proceso de patrimonialización independiente del marco normativo impuesto por los programas de la Unesco (en sentido amplio)" (Bortolotto, 2011 , p. 25), en un constante vaivén entre la autodesignación por parte de los actores mismo y la validación-difusión internacional de la práctica por los Estados (Grenet \& Hottin, 2011).

Como se mencionó anteriormente, el término de patrimonio cultural inmaterial tiene una estrecha relación con la concepción de la cultura; por ello, frente a la concepción "abstracta" (Mead, Benedict, Linton) y simbólica (Clifford Geertz) retomo las propuestas de la antropología cognitiva, especialmente lo propuesto por Claudia Strauss y Naomi Quinn (2003), para analizar al PCI en tanto producto de los esquemas culturales. Estas autoras, proponen que los significados están basados en esquemas culturales que se construyen con base en la percepción de la realidad, posibilitan la definición de la identidad, orientan la acción y explican los comportamientos; todo ello mediado por la experiencia a partir de un modelo conexionista.

\section{Los significados generados por los esquemas, en los modelos conexionistas, son estados mentales que son formados a partir de las experiencias de vida especificas de quienes los aprenden y son sensibles a la actividad en un contexto particular (Strauss \& Quinn, 2003, p. $50)$.}

Esta aproximación teórica permite comprender y explicar las formas de creatividad cultural, las prácticas performáticas dotadas de significado y sentido, la transmisión de los significados culturales; es decir, de qué manera se crea el patrimonio inmaterial en tanto práctica cultural resultante de los esquemas culturales. Así mismo, es posible comprender al PCI como la forma extrema de objetivación metacultural de la cultura en su sentido antropológico (Bortolotto, 2011), es decir, se objetivizan esquemas interiorizados de los agentes portadores de cultura.

Así, en 2003, la UNESCO instituye la Convención para la Salvaguardia del Patrimonio Cultural Inmaterial, la cual tiene sus principios en el reconocimiento de la diversidad cultural y la creatividad humana; así como la necesidad de reconocer las prácticas culturales, los derechos humanos y culturales, el desarrollo sostenible y como herramienta para combatir los impactos negativos de la globalización en este tipo de patrimonio (United Nations Educational Scientific and Cultural Organization [UNESCO], 2003). En este sentido, "el actual interés en el patrimonio inmaterial está arraigado en una tendencia de finales del siglo XX de reevaluar los beneficios de la modernidad, expresa un miedo por los efectos de la globalización y la búsqueda por las identidades locales a menor escala" (Deacon, Dondolo, Mrubata \& Prosalendis, 2004, p. 7), por lo cual se plantea la necesidad de salvaguardarlo.

Dicha Convención generó una serie de instrumentos de salvaguardia de las prácticas inmateriales: la Lista Representativa (LR), la Lista de Salvaguardia Urgente (LSU) y el Registro de Mejores Prácticas de Salvaguardia (MPS); hasta 2015, existen trescientas noventa y una manifestaciones del patrimonio cultural inmaterial (PCI) inscritas en dichas listas. En el caso mexicano, existen ocho elementos inscritos en la Lista Representativa ${ }^{i}$ y uno en el Registro de Mejores Prácticas de Salvaguardiaii. 
Esta Convención y las políticas culturales "extraterritoriales", como lo plantea Bauman (2004, 2015), generadas en la UNESCO, responden a la necesidad de crear conciencia acerca de la importancia de la protección del patrimonio cultural, y de establecer principios comunes alrededor del mundo; bajo la creación de valores universales de autenticidad (presente en la Convención de 1972) y representatividad (en la Convención de 2003). Ésta última, "establece que las manifestaciones del patrimonio cultural tienen un valor universal debido al valor intrínseco que tienen para las comunidades locales que las abrigan y las practican" (Duvelle, 2011, p. 21); buscando que los valores locales se conviertan en globales. Retomando a Bauman (2015), "la idea de 'universalización' transmitía la esperanza, la intención y la resolución de crear el orden; por encima de lo que indicaban los términos afines, significaba un orden universal: la creación de orden en una escala universal, verdaderamente global" (Bauman, 2015, pp. 80-81).

Por otro lado, existe un proceso de valoración en el sentido contrario; en el que los valores "universales" se interiorizan reconfigurando las significaciones y procesos de construcción del patrimonio cultural. Adoptando la idea de lo patrimonial "según la UNESCO" y buscando su reconocimiento global; desplazando las valoraciones que los constituían en patrimonios locales a una que los convierten en patrimonios localizados. Es decir, este patrimonio local que puede ser entendido a partir de la puesta en valor jerarquizada de los elementos culturales dados a partir de la memoria compartida y su significación, el cual se conforma como un soporte de procesos identitarios y cuyo interés puede ser escaso más allá de la comunidad; pasa a ser patrimonio localizado cuando el interés hacia él "trasciende su ubicación y es capaz de provocar por sí mismo flujos de visitantes con relativa independencia de la misma" (Prats, 2005, p. 24). En el cual la valoración externa puede no coincidir con las interpretaciones del mismo en un nivel local y estar en una situación de fricción; esto propicia el desarraigo de su entorno, sus actores y de todos los elementos que los dotan de sentido y favorece procesos de turistificación y explotación turística de las prácticas culturales.

Harrison (2013) plantea que "las tradiciones y aspectos cotidianos de la cultura son raramente concebidos como 'patrimonio' en ausencia de incertidumbre, riesgo, la percepción de amenaza o la necesidad de competir por la atención con otros intereses, que son percibidos como perjudiciales para ellos" (Harrison, 2013, p. 18); es decir, es un patrimonio vivo que es creado y recreado continuamente. Sin embargo, en el proceso de oficialización de este patrimonio inmaterial, existe una patrimonialización nostálgica; en la que se apela a este temor a la pérdida de las prácticas culturales como elemento para su preservación según los cánones del patrimonio oficial.

Es este miedo ante la incertidumbre del futuro el motor de la puesta en valor del patrimonio inmaterial, buscando que conforme un elemento de arraigo y de asentamiento de las identidades locales, como lo menciona Deacon et al. (2004) y como un motivo para proteger aquello que aún da estabilidad y seguridad a las sociedades actuales, o como menciona Huyssen (2002), en su análisis acerca de los museos, que "no es la conciencia de tradiciones seguras lo que marca los comienzos del museo, sino su pérdida, combinada con un deseo estratificado de (re)construcción" (Huyssen, 2002, p. 44). Es a partir de la sensación de pérdida e incertidumbre que se piensa en la protección de los elementos asociados a un pasado; en cierto sentido, "tiene que ver con la repetición de lo irrepetible, con la materialización de lo inmaterial" (Boym, 2015, p. 18).

\section{La patrimonialización en red}

La globalización es un proceso que se ha caracterizado por la licuefacción de las estructuras sólidas de la sociedad (Bauman, 2004, 2015), transformando sustancialmente los procesos económicos, tecnológicos, políticos y culturales; muestra de ellos es el debilitamiento del Estado. Este cambio global podría caracterizarse por una tensión entre lo global, lo local, lo público, lo privado y lo colectivo; en la que se generan dinámicas de apertura, exclusión, reterritorilaización, arraigo y violencia.

La propia fluidez de la sociedad actual, la desarticulación de las estructuras y "las fuerzas de la globalización promovieron las condiciones para el crecimiento de la incertidumbre social a gran escala y para el incremento de la fricción de lo incompleto [...]" (Appadurai, 2013, p. 23). Esta situación de incertidumbre del futuro y el riesgo de pérdida está presente en las dinámicas en las cuales la cultura se ha insertado.

Es posible comprender al PCI como reflejo de la sociedad global, en la cual la producción de localidad, translocalidad y un proceso de patrimonialización en red serán característicos. El cual es cambiante, dinámico, atemporal (del pasado, del presente y del futuro), requiere o no de un territorio específico (como puede verse en el caso de los procesos de reterritorialización de algunas prácticas culturales de migrantes mexicanos en Estados Unidos) y se 
relaciona con procesos de fricción o conflicto. Es decir, en términos de la fluidez planteada por Bauman (2004, 2015), se podría concebir al patrimonio como un patrimonio líquido.

A pesar de estos procesos devastadores y preservadores del patrimonio cultural, Cristina Amescua (2011) plantea que "la globalización es el medio de contraste que permite a las culturas verse y saberse, encontrarse y descubrirse. Las diferencias y similitudes se hacen visibles en los infinitos contactos cotidianos locales-globales" (Amescua, 2011, p. 120). Podría decirse que el patrimonio inmaterial surge en los procesos de interacción y de fricción, entendida como "las cualidades incómodas, desiguales, inestables y creativas de la interconexión a través de la diferencia" (Tsing, 2005, p. 4).

Por otro lado, en relación con el sentimiento de riesgo, pérdida e incertidumbre del futuro generado por los procesos de globalización, existe un proceso de búsqueda de arraigo y pertenencia en la cultura propia. Este proceso de retorno a lo local, simultaneo a mirar lo global, es un hecho en el cual se detona y denota la identidad de los agentes culturales, es decir, genera, reconoce, promueve y exalta procesos identitarios; echan mano de sus prácticas y acervos culturales para enfrentarse, encontrarse y comprender los cambios globales.

Estos actos son visibles en lo que podría denominarse el patrimonio translocal; es decir la producción de patrimonio en un contexto o espacio translocal, "fuera" de su lugar de "origen", ocasionado por la movilidad humana y de sus prácticas culturales. Retomando a Appadurai (1999, p. 111), "son mundos existenciales constituidos por asociaciones relativamente estables, historias relativamente conocidas y compartidas, y espacios y lugares recorridos y elegibles colectivamente [...]".

La patrimonialización puede ser entendida como el proceso de construcción de significado y sentido de los elementos culturales, a través de la asignación de valores, que los agentes culturales hacen con ciertas finalidades. Así mismo, retomo la conceptualización que plantea Harrison (2013) acerca del patrimonio cultural; en el que

no es un proceso pasivo de solo conservar las cosas del pasado que quedan, sino un proceso activo de ensamblaje de una serie de objetos, lugares y prácticas que elegimos soportar como un espejo al presente, asociado a un conjunto particular de valores que deseamos tomar con nosotros para el futuro (Harrison, 2013, p. 4)

En este sentido, retomando lo planteado por Castells (2009) acerca de la sociedad red, "formada por configuraciones concretas de redes globales, nacionales y locales en un espacio multidimensional de interacción social" (Castells, 2009, p. 44), podríamos hablar de un proceso de patrimonialización en red; en la cual diversos actores confluyen en un sistema organizado en redes, nodos y flujos. Redes o enlaces que conectan o no a actores en el proceso de atribuirle valor a una práctica cultural específica; con nodos interconectados con mayor o menor importancia; en donde lo que fluye son valores, intereses y significados que conectan o desconectan actores; una red que siempre está en continua reconfiguración.

Existen actores "internacionales" (como la UNESCO) que se vinculan con los gobiernos nacionales (a través de sus instituciones), que se vinculan o no con las instituciones locales y los agentes portadores de cultura; en la cual también se relacionan asociaciones civiles, organizaciones empresariales y otros actores que no participan directamente del patrimonio; donde los valores se reconfiguran y fluyen, concibiendo a la patrimonialización como un proceso no lineal, con una multiplicidad de actores y sitios desde los cuales se constituye.

Es importante destacar que se hablará de agentes de la cultura, en vez de portadores de cultura, ya que concebir a los sujetos como agentes hace referencia a entender a estos como individuos actuantes con capacidad de decisión y acción sobre sus elementos culturales, enfatizando en la posibilidad de hacerpatrimonio.

Retomando la idea de la patrimonialización en red, es posible comprenderla a partir de la propuesta de Deleuze y Guattari (2016) respecto al rizoma, la cual podría ser considerada como un espacio de comunicaciones transversales, intercambiables, múltiples y que no cuentan con un centro; "se trata del modelo que no cesa de constituirse y destruirse, y del proceso que no cesa de extenderse, interrumpirse y recomenzar" (Deleuze \& Guattari, 2016, p. 58). Las características de este modelo son una multiplicidad de flujos, direcciones cambiantes e intercambiables, sin un centro, establecida a partir de relaciones y conexiones transversales (interconexión), con reconfiguraciones $y$ reconstrucciones continuas.

En este sentido es posible comprender a los procesos de construcción del patrimonio dentro de este modelo, en el cual el punto de convergencia son las prácticas o elementos culturales que serán sujeto del proceso. Donde actores interconectados entre sí o no, confluyen o divergen en las motivaciones, significaciones y finalidades de la patrimonialización. Se podría decir que este flujo (de significados y valores) recorre las líneas que conectan a los actores y confluyen a través de los elementos culturales generando patrimonio. Este 
proceso, como se mencionó, no es fluido per se, existen fricciones, conflictos y mediaciones en torno a la significación y patrimonialización resultante.

Cabe recalcar que el rizoma "se remite a un mapa que debe ser producido, construido, siempre desmontable, conectable, alterable, modificable, con entradas y salidas múltiples, con sus líneas de fuga" (Deleuze \& Guattari, 2016, p. 60) y que, en el caso de existir una ruptura de las conexiones, siempre se generan nuevas a partir de esta.

Esto en términos patrimoniales significaría que, si una práctica cultural pierde significación por la interrupción del flujo de ciertos actores, es posible que se generen nuevas significaciones e interconexiones de dichos significados; a partir de esto, es posible comprender las rupturas generacionales con la tradición, en donde las generaciones más jóvenes generan nuevas redes y conexiones bajo nuevos significados y valores. Esta propuesta puede ser visualizada en el siguiente esquema (ver Figura 1) en el cual se muestran las interacciones, desconexiones y vínculos parciales entre algunos actores en el proceso de la patrimonialización en red. referentes patrimoniales se realiza en una escala local, los cuales pueden ser comprendidos en términos generales como transmisores, participantes y practicantes de los elementos culturales; los cuales crean y dotan de sentido y significado a dichos elementos configurando una patrimonialización primaria.

Así mismo, existen otros actores independientes, pero ocasionalmente relacionados entre sí como las Organizaciones No Gubernamentales (ONG) y de la sociedad civil y las instancias académicas; que a partir de procesos de colaboración con los agentes culturales generan una patrimonialización cogestiva (a partir de los procesos gestión de las ONG), una patrimonialización académica (desde las investigaciones y significaciones provenientes de las indagaciones académicas) o una patrimonialización religiosa (desde la significación relacionada con la religión). De igual forma, a partir de los efectos generados por el fomento del turismo cultural y la inserción del PCI en las esferas de consumo de la sociedad y la iniciativa privada, se podría hablar de una patrimonialización para el consumo, la cual es generada a partir de la construcción narrativa, discursiva y audiovisual (transmedia) de las prácticas

Figura 1 - Esquema de la patrimonialización en red

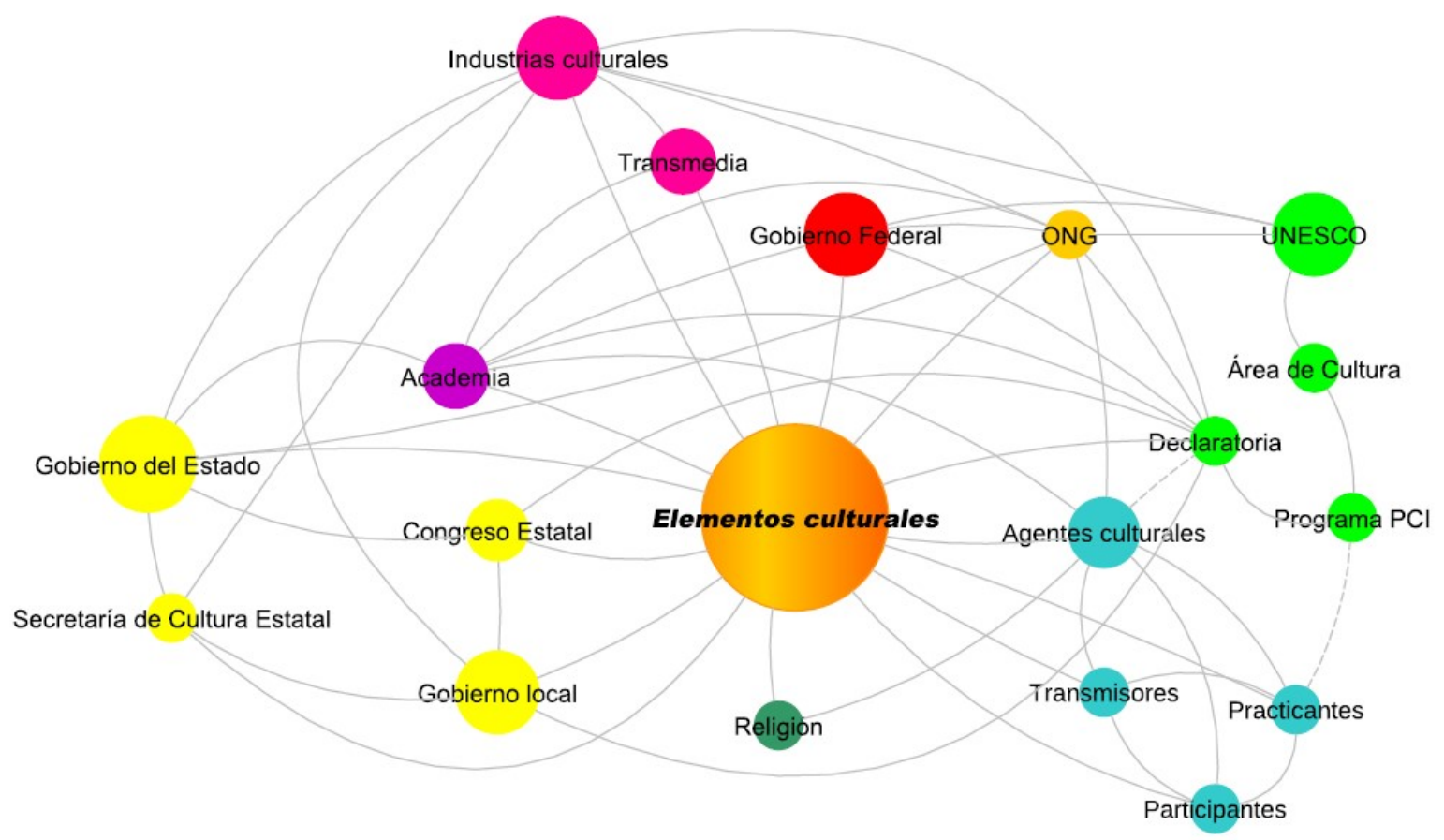

Fuente: Elaboración propia, 2018

En este sentido, hay un primer proceso de patrimonialización por parte de los agentes portadores de la cultura, cuya puesta en valor de los inmateriales que en muchas de las ocasiones están disociadas de los significados interiorizados de los mismos. Así mismo, "las activaciones patrimoniales 
han adquirido otra dimensión, han entrado abiertamente en el mercado y han pasado a evaluarse en términos de consumo" (Prats, 2005, p. 22), favoreciendo su espectacularización, la transformación del patrimonio en mercancía y reduciendo la polisemia de los elementos culturales.

Por otro lado, está la patrimonialización institucional que es generada a través de los dispositivos culturales y legislativos de los Estados, es un proceso que se $\mathrm{da}$ a partir del reconocimiento, visibilidad y difusión de los elementos culturales, impulsado por diversas instancias de gobierno local, regional y nacional, así como de las instancias encargadas de la política cultural en dichos niveles.

Por último, es posible hablar de una patrimonialización global a partir de los marcos normativos generados, particularmente, por la UNESCO. Quien a partir del establecimiento de ciertos criterios y requisitos "promueven tecnologías para producir pasados y futuros, por los cuales significamos archivos, artefactos, prácticas rituales, performances, y espacios materiales" (Rowlands \& de Jong, 2009, p. 15); patrimonializando a través de dispositivos tales como las declaratorias y la inscripción en las Listas de Patrimonio de la Humanidad.

\section{Xantolo, patrimonialización en red}

En los últimos años, el Día de Muertos ha cobrado visibilidad internacional debido a la representación de esta festividad a través de películas como Coco (Disney) en 2017 y Spectre, película de James Bond en 2015. En esta última, especialmente se muestra al Día de Muertos como una festividad carnavalesca, con desfiles y espectáculos en las principales calles de la ciudad. Efecto de esta producción cinematográfica fue que en 2016 se organizara por primera vez un desfile con motivo del día de muertos nombrado "Desfile de Día de Muertos Carnaval de Calaveras" que recorrió el Paseo de la Reforma para llegar al Zócalo de la Ciudad de México; generando una política de difusión turística por parte de la Secretaría de Turismo federal, tratando de mostrar lo que en dicha película se suponía que conformaba dicha festividad.

Por ejemplo, en el caso del Xantolo (expresión de la región huasteca del Día de Muertos) es posible reconocer a los diferentes actores que forman parte de la patrimonialización en red. La celebración comienza el día 24 de junio con una serie de preparativos para las fechas principales del 1 y 2 de noviembre, terminando el día 30 de noviembre con el Xantolo chiquito. Esta práctica se da en los ámbitos privados (con la colocación de una ofrenda y arcos florales en las casas $\mathrm{y}$, en menor medida, en los panteones) y públicos (con la exaltación colectiva de la conmemoración, a través de danzas y actos comunitarios). Particularmente, abordaré el caso del Xantolo en el contexto del municipio de Huejutla, Hidalgo; en donde año con año se realiza una fiesta dedicada a los muertos en la cual se realizan concursos de cuadrillas de danza xantolera, certamen de Señorita Cempoalxochitl y una serie de eventos culturales en torno a la festividad del día de muertos; asemejando a cualquier otra fiesta patronal.

Cabe mencionar que el Xantolo fue declarado Patrimonio Cultural Inmaterial del Estado de Hidalgo el 29 de octubre de 2015, por parte del Congreso del Estado, con base en valores de pertenencia, representatividad y conformación identitaria. Si bien existe este reconocimiento estatal, a nivel local los valores patrimoniales que los agentes de esta festividad establecen tienen relación con el valor de resistencia y defensa de la identidad huasteca frente al "robo de los extranjeros".

Esta festividad "es de enorme importancia entre las sociedades indígenas de la región Huasteca de México" (Lara, 2013, p. 53) Potosina, Veracruzana e Hidalguense -, en la que se conmemora el regreso de los seres queridos que han fallecido; forma parte de las diversas manifestaciones sobre el día muertos en el país. Dicha festividad es similar en los municipios que conforman la región; colocan arcos y ofrendas que difieren en su diseño y en algunos elementos que son colocados en la misma. Por otro lado, existe la presencia de grupos de danzantes, cuadrillas o comparsas que se diferencian una de otra por los personajes que las integran o el son que bailan.

La fiesta del Xantolo se celebra de manera peculiar en la huasteca hidalguense; a diferencia de las prácticas relacionadas con el Día de Muertos en las demás regiones que conforman el estado de Hidalgo, los preparativos para dicha festividad inician desde mitad de año siendo la fiesta más importante para los huastecos. En donde "el tiempo y el espacio familiares y comunitarios se transforman" (Jurado, 2001, p. 107), constituyéndose como "la fiesta con mayor poder de convocatoria para reunir a todos aquellos que han tenido que salir de la localidad" (Sevilla, 2002, p. 60). en este caso se abordan las particularidades de la misma, en tanto patrimonio cultural inmaterial, en el municipio de Huejutla, Hidalgo.

El Xantolo es relevante en términos sociales y económicos, al constituirse como el tiempo de gran actividad comercial en las cabeceras municipales donde los artesanos y campesinos venden parte de sus cosechas de frutas y flores, así 


\section{Jesús Mendoza Mejía}

como de los objetos artesanales que son necesarios para llevar a cabo la festividad. Por otro lado, es la ocasión de retorno de los emigrados que regresan para celebrar con los familiares.

Figura 2 - Ofrenda durante el ritual de Bajada de Máscaras - Huejutla, Hidalgo, México

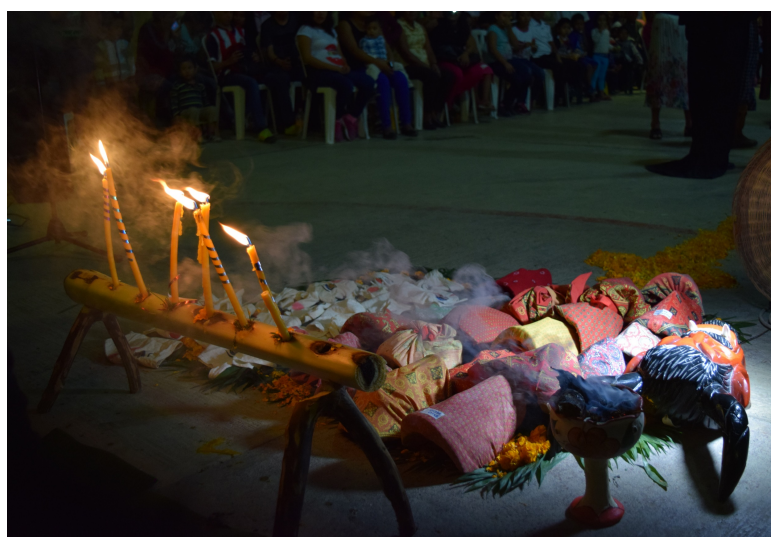

Fuente: Jesús Mendoza Mejía (2017)

El inicio de la festividad es el día 24 de junio, día dedicado a San Juan Bautista, en donde se comienzan los preparativos de la siembra de la flor de muerto o cempoalxóchitl; el 29 de junio, día de San Pedro y San Pablo, se inicia la crianza de marranos, guajolotes, gallinas y pollos para la preparación de las ofrendas; y el 29 de septiembre, San Miguel Arcángel, se realiza la Primera Ofrenda a medio día con café, tamales y pan que son ofrecidos a las personas. Posteriormente el $18 \mathrm{de}$ octubre se realiza la segunda ofrenda, las dos ofrendas son organizadas y montadas por trabajadores de la Casa de Cultura del gobierno municipal en la explanada principal del centro de Huejutla. Este mismo día, las cuadrillas de disfrazados realizan el ritual de la "bajada de máscaras", la cual es organizada por los miembros de las cuadrillas en canchas, kioskos o plazas de las colonias de las que provienen.

El 30 de octubre se considera el "Día de las flores" en donde las personas realizan la compra de flores de cempoaxóchitl o pata de elefante, para elaborar los arcos y adornar las ofrendas para que el 31 de octubre (día dedicado a los angelitos), el 1 de noviembre (dedicado a los difuntos grandes) y el 2 de noviembre (dedicado al Ánima sola), los seres queridos regresen. Para terminar con la fiesta el día 30 de noviembre (día de San Andrés), en el que se hace el "destape de disfrazados" y la ofrenda del Xantolo Chiquito.

En este sentido, en tanto patrimonialización primaria es posible comprender el papel de las cuadrillas, conformadas en su mayoría por jóvenes entre ocho y treinta y cuatro años, quienes durante la festividad del Xantolo forman parte de las cuadrillas de disfrazados o viejos que recorren el
Reflexiones en torno a los procesos de patrimonialización municipio danzando en las ofrendas colocadas en los hogares que solicitan su asistencia.

Estas cuadrillas se reúnen cada semana para ensayar en su tiempo libre, especialmente cuando las fechas del Xantolo están cerca, donde se esfuerzan para así poder representar de manera respetuosa las danzas que les fueron transmitidas por sus abuelos; repitiendo una y otra vez el son hasta que todos los miembros dancen de manera coordinada, lo cual habla de la importancia que tiene la práctica para ellos. Cabe mencionar que anteriormente eran las personas adultas las que participaban y se disfrazaban en las cuadrillas, ahora los jóvenes representan el grueso de la población que las integra. A la vez que se conforman como practicantes, se convierten en transmisores del PCI al mostrar a los nuevos integrantes la manera en la que se debe zapatear o valsear.

Los miembros de las cuadrillas destacan la importancia que tiene su participación en el Xantolo, ya que marcan a través de su danza el inicio y final de la festividad, marcan el tiempo ritual de la misma.

De igual forma están presentes los músicos que acompañan a las cuadrillas tocando los sones xantoleros (como "Los matlachines", "El gallito", "Xochipitsahua", "El guajolote", "El cuanegro", entre otros), en el cual ejecutan un amplio repertorio musical e inclusa innovan con la creación de sones en los que se inspiran por sucesos recientes en la región, como el caso del son "El conjuntivitis", creado en 2017 por Don Filegonio tras un brote de casos de dicho padecimiento en la región.

Figura 3 - Concurso de Cuadrillas Huejutla, Hidalgo, México

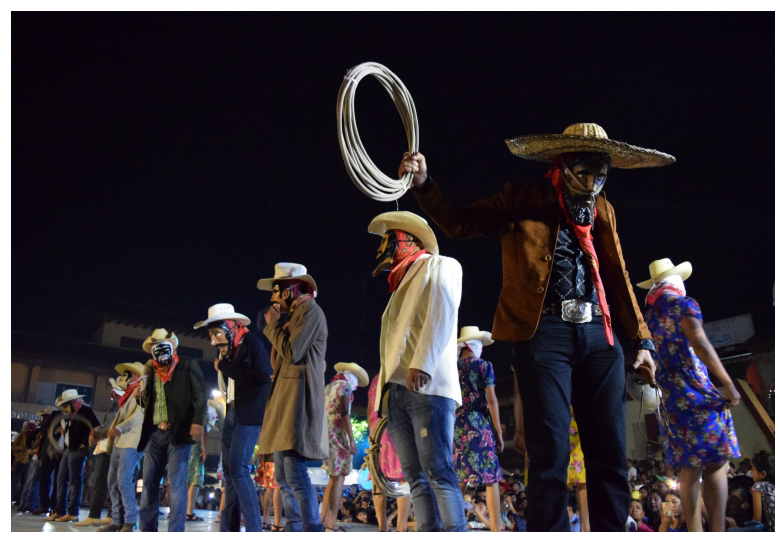

Fuente: Jesús Mendoza Mejía (2017).

Así mismo, los artesanos que realizan las máscaras de madera que son usadas por las cuadrillas, quienes junto a los alfareros de la comunidad de Chililico y a pesar de la extensa 
producción de máscaras o adornos de plástico buscan comerciar sus productos y obtener el reconocimiento por la destreza empleada en la creación de artesanías de barro y madera.

Por otro lado, también se encuentran quienes tal vez no practican dentro de las cuadrillas o crean elementos indispensables para la celebración de la festividad pero que fomentan y participan de la misma. $\mathrm{Al}$ apoyar a sus familiares o amigos pertenecientes a las cuadrillas del municipio, colaborando en el montaje de arcos y ofrendas, asistiendo y viviendo el patrimonio inmaterial en los panteones o en las plazas públicas. En este mismo sentido se inserta la participación de la iglesia en la patrimonialización religiosa; si bien no existe una relación cercana en torno a la conmemoración del Xantolo, existe la articulación de dicha práctica con el ritual litúrgico del Día de Todos los Santos y Fieles Difuntos de la religión católica.

Por su parte, el gobierno municipal y el estatal, a parte de los proyectos y acciones de la política cultural que ejecutan para la protección del patrimonio, organizan una serie de eventos y concursos que se integran en las actividades que conforman al Xantolo. Esta patrimonialización institucional visibiliza, reconoce y difunde la festividad.

Por ejemplo, en el caso del municipio de Huejutla, se instala una escenografía en la que se colocan elementos que constituyen a la práctica del Xantolo (alfarería, cerería, cestería, creación de textiles, procesos de siembra de flor de cempoalxóchitl, danzas, etc.) con el motivo de atraer a los habitantes del municipio y a visitantes de la religión en participar de la festividad en un contexto público. Así mismo, existe la búsqueda de reconocimiento regional en 2015 a través la declaratoria de patrimonio inmaterial por parte del Congreso del Estado de Hidalgo.

De ahí, y aunado a la reciente visibilidad de eventos a nivel nacional en torno al Día de Muertos (la aparición de la práctica en la película Spectre de la saga de James Bond y su posterior adaptación en la capital del país, la película Coco de Disney o los diversos proyectos organizados en los estados que llevan a cabo dicha práctica), el gobierno estatal buscó en 2017 el Record Guinness de la Ofrenda más grande del mundo. Formando representaciones espectacularizadas que tienden a difuminar la diversidad de significados asignados por parte de sus portadores.

Esto se vincula con la patrimonialización para el consumo, por un lado, a través del reciente desarrollo de estrategias para el fomento turístico en torno al Xantolo en el Estado de Hidalgo. Dentro de este tipo de construcción del patrimonio está presente la creación de mercancía xantolera (playeras serigrafiadas, borras bordadas, tazas, etc.) que son consumidos por locales y externos con la finalidad de adquirir un recuerdo de la festividad.

Así mismo, se encuentran las producciones locales de narrativas audiovisuales de los Concursos de cuadrillas que son comercializados en el mercado y negocios de música y películas en el municipio de Huejutla. dentro de estos registros audiovisuales es posible conocer las narrativas, construcciones y significaciones del Xantolo para las cuadrillas de las diversas localidades y barrios del municipio que participan en dichos concursos.

Cabe resaltar la importancia de estas producciones ya que impactan en la formación e integración de cuadrillas, ya que quienes consumen los DVD's en mayor medida son jóvenes pertenecientes a centros educativos de nivel medio superior y superior para aprehender las danzas xantoleras y así poder participar dentro de los concursos que organizan sus escuelas. Frente a la idea de la venta de la cultura a través de estos medios, los agentes culturales que están inmersos en la práctica del Xantolo ven con buenos ojos éstos materiales que propician su difusión, salvaguardia, transmisión y la generación de nuevos creadores y practicantes del patrimonio inmaterial.

En este sentido de la producción de narrativas, está presente el uso de las redes sociales a través de las cuales se difunden fotografías y videos de las prácticas inmateriales del Xantolo; por medio de las cuales las nuevas generaciones estarán practicando, recreando, significando, transmitiendo, preservando, difundiendo y valorando su patrimonio cultural inmaterial.

En términos de la patrimonialización global, el Xantolo se enmarca como una de las expresiones regionales de la "Festividad Indígena dedicada a los muertos", proclamada el 7 de noviembre de 2003 como Obra Maestra del Patrimonio Oral e Inmaterial de la Humanidad, en un contexto en el que por primera vez en la historia se puso una ofrenda de muertos en Los Pinos (Lomnitz, 2013, p. 434) y en donde una serie de reformas constitucionales, aunadas a esta candidatura, buscaban mejorar la imagen y las relaciones del gobierno mexicano con las comunidades indígenas.

Dicha proclamación fue apoyada por un grupo de investigadores, instituciones culturales y actores vinculados con la promoción y protección del patrimonio; a partir de la cual la manifestación "acrecienta su valor social, su reconocimiento estético y su relevancia política internacional" (Arizpe, 2011a, p. 68) y debido a que la lógica bajo la cual trabajaba el Programa de Proclamación de Obras Maestras no concebía la participación de las comunidades portadoras en la constitución de la iniciativa como factor decisivo para su reconocimiento por parte d la UNESCO. 
De ahí la relevancia de la patrimonialización académica, ya que se seleccionó dicho elemento en términos de la relevancia de su práctica en gran parte del territorio mexicano y a su fortaleza en el sentido de la diversidad de investigaciones académicas existentes en torno al Día de Muertos. De igual forma, la producción de documentales que construyen narrativas audiovisuales y representaciones en torno a la festividad. Por ejemplo, las producciones Miikailhuit. Xantolo. El retorno de los muertos, de María Eugenia Jurado y Andrea Marichal; así como De Carnaval a Xantolo del Programa de Desarrollo Cultural de la Huasteca en las que se plantean, de forma académica y desde la antropología las diversas formas de expresar el día de muertos en comunidades huastecas.

Empero las implicaciones e impactos que genera el reconocimiento e inscripción de elementos del PCI ante la UNESCO, como en el caso del Comité Central de Comparsas del municipio de Tempoal, Veracruz, está latente la articulación-conexión que estos agentes culturales están generando para fomentar la iniciativa de obtener el reconocimiento a nivel estatal, nacional e internacional a través de acciones que ponen en valor la práctica, favorecen el fortalecimiento de las identidades locales y propician el reconocimiento de los valores presentes en las danzas de Xantolo.

\section{Conclusiones}

Comprender a la patrimonialización como proceso que ocurre en red brinda la oportunidad de reflexionar entorno a la diversidad de actores que son partícipes, en las que es posible ver las conexiones existentes entre ellos, así como los valores y significados que generan; aportando elementos para el análisis de la dinamicidad del patrimonio cultural inmaterial, así como de la generación de un mapeo de agentes culturales involucrados en ciertos procesos de patrimonialización. Cabe resaltar que los procesos de patrimonialización en red no son libres de fricciones o controversias en cuanto a los términos bajo los cuales se patrimonializa.

De igual forma, a partir de los diferentes tipos de patrimonialización que se proponen es posible analizar las reconfiguraciones y significaciones de las prácticas culturales desde aspectos poco visitados para comprender los procesos de construcción del patrimonio cultural inmaterial; por ejemplo, en términos de su ensamblaje en las producciones transmediáticas, presentes en los medios de comunicación o el uso de las redes sociales.

\section{Referencias bibliográficas}

Amengual, G. (2008). Pérdida de la experiencia y ruptura de la tradición. La experiencia en el pensamiento de Walter Benjamin. In Amengual, G., Cabot, M., Vermal, J. L. (Eds.). Ruptura de la tradición. Estudios sobre Walter Benjamin y Martin Heidegger (pp. 29-59). Madrid: Trotta.

Amescua, C. (2011). Análisis regional de las proclamaciones de Obras Maestras del Patrimonio Oral e Inmaterial de la Humanidad. In Arizpe, L. (Coord.). Compartir el patrimonio cultural inmaterial: narrativas y representaciones (pp. 103-128). México: Dirección General de Culturas Populares/CONACULTA-Centro Regional de Investigaciones MultidisciplinariasUNAM.

Appadurai, A. (1999). Soberanía sin territorialidad. Notas para una geografía posnacional. In Nueva Sociedad, (pp. 109-124).

(2013). El rechazo de las minorias. México: Tusquets Editores.

Arizpe, L. (2006). Culturas en movimiento. Interactividad cultural y procesos globales. México: Cámara de Diputados, LIX Legislatura-UNAM/CRIMMiguel Ángel Porrúa.

. (2011a). El patrimonio cultural inmaterial de México. Ritos y festividades. México: Miguel Ángel Porrúa-CRIM/UNAM.

(2011b) (Coord.). Compartir el patrimonio cultural inmaterial: narrativas y representaciones México: DGCP/CONACULTA-CRIMUNAM.

Bauman, Z. (2004). Modernidad líquida. Argentina: FCE.

(2015). La globalización: consecuencias bumanas. México: FCE.

Bondaz, J., Isnart, C., \& Leblon A. (2012) Au-delà $\mathrm{du}$ consensus patrimonial: Résistances et usages contestataires du patrimoine. Civilisations, (61, pp. 9-22).

Bonfil, G. (2004). Implicaciones éticas del sistema de control cultural. In Olivé, L. (Comp.). Ética y diversidad cultural (pp.-). México: FCE.

Bortolotto, C. (2011). Le trouble du patrimoine culturel immatériel. In Bortolotto, C. (Ed.). Le patrimoine culturel immatériel. Enjeux d'une nowvelle catégorie (pp.21-43). Paris: Éditions de la Maison des sciences de l'homme.

Boym, S. (2015). El futuro de la nostalgia. España: A. Machado Libros.

Castells, M. (2009). Comunicación y poder. España: Alianza Editorial.

Choay, F. (2007). Alegoría del patrimonio cultural. Barcelona: Gustavo Gili.

Deacon, H., Dondolo, L., Mrubata, M., \& Prosalendis, S. (2004). The subtle power of 
intangible heritage: Legal and financial instruments for safeguarding intangible heritage. South Africa: Human Sciences Research Council Publishers.

Deleuze, G., \& Guattari, F. (2016). Riz̧oma. México: Fontamara.

Duvelle, C. (2011). Los instrumentos normativos internacionales de la UNESCO sobre la cultura: una mirada al pasado, una mirada al futuro. In Arizpe, L. (Coord.). Compartir el patrimonio cultural inmaterial: narrativas $y$ representaciones (pp.15-24). México: DGCP/CONACULTA-CRIM-UNAM.

Grenet, S., \& Hottin, C. (2011). Avant-propos. Un livre politique. In Bortolotto, C. (Ed.). Le patrimoine culturel immatériel. Enjeux d'une nouvelle catégorie (pp.9-19). Paris: Éditions de la Maison des sciences de l'homme.

Harrison, R. (2013). Heritage. Critical approaches. Estados Unidos: Routledge.

Huyssen, A. (2002). En busca del futuro perdido. Cultura y memoria en tiempos de globalización. México: FCE.

Jurado, M. E. (2001). Xantolo: el retorno de los muertos. México: FONCA/CONACULTA.

Kearney, A. (2009). Intangible cultural Heritage. Global awareness and local interest. In Smith, L. Akagawa, N. (Eds.). Intangible Heritage (pp. 209-225). Estados Unidos: Routledge.

Lara, J. (2013). ¡Cuabuebue tlaquastecapantlalli! La Danza de Cuanegros. Testimonio Musical de México, 60. México: INAH.

Lomnitz, Claudio (2013). Idea de la muerte en México. México: FCE.

Mosterín, J. (1993). Filosofía de la cultura. España: Alianza Editorial.

Prats, L. (1997). Antropología y patrimonio. España: Ariel.

(2005). Concepto y gestión del patrimonio local. Cuadernos de Antropología Social, (21), 17-35.

Rowlands, M. \& de Jong, F. (2009) Reconsidering heritage and memory. In de Jong, F. \& Rowlands, M. (Eds.). Reclaming heritage: alternative imaginaries of memory in West Africa (pp.13-29). Estados Unidos: Left Coast Press.

Sevilla, A. (2002). De Carnaval a Xantolo: contacto con el inframundo. México: Programa de Desarrollo Cultural de la Huasteca.

Sims, M. C. (2005). Living folklore: an introduction to the study of people and their traditions. Estados Unidos: Utah State University Press.

Smith, L. (2006). Uses of heritage. Estados Unidos: Routledge.

Akagawa, N. (2009) (Eds.). Intangible

Heritage. Estados Unidos: Routledge.
Reflexiones en torno a los procesos de patrimonialización

Strauss, C., \& Quinn, N. (2003). A cognitive theory of cultural meaning. Reino Unido: Cambridge Univerity Press.

Tsing, A. L. (2005). Friction: an ethnography of global connection. Estados Unidos: Princeton University Press.

United Nations Educational Scientific and Cultural Organization (2003). Convención para la Salvaguardia del Patrimonio Cultural Inmaterial. Paris: UNESCO.

\section{Notas}

${ }^{i}$ Las fiestas indígenas dedicadas a los muertos (2008), Lugares de memoria y tradiciones vivas de los otomi-chichimecas de Tolimán: la Peña de Bernal, guardiana de un territorio sagrado (2009), La ceremonia ritual de los Voladores (2009), Los parachicos en la fiesta tradicional de enero de Chiapa de Corzo (2010), La pirekua, canto tradicional de los p'urhépechas (2010), La cocina tradicional mexicana, cultura comunitaria, ancestral y viva - El paradigma de Michoacán (2010), El Mariachi, música de cuerdas, canto y trompeta (2011), La charrería, arte ecuestre y vaquero tradicional de México (2016).

ii Xtaxkgakget Makgkaxtlawana: el Centro de las Artes Indígenas y su contribución a la salvaguardia del patrimonio cultural inmaterial del pueblo totonaca de Veracruz, México (2012). 